\title{
Patient Outcomes, Health Care Resource Use, and Costs Associated with High Versus Low HEDIS Asthma Medication Ratio
}

\author{
Allan T. Luskin, MD; Evgeniya N. Antonova, MS, PhD; Michael S. Broder, MD, MSHS; \\ Eunice Chang, PhD; Karina Raimundo, MS; and Paul G. Solari, MD
}

\begin{abstract}
BACKGROUND: The Healthcare Effectiveness Data and Information Set (HEDIS) quality measures for asthma include the asthma medication ratio (AMR) as a marker of quality of care for patients with asthma. Few data are available to describe the association between health care use and costs in patients with high versus low AMR.

OBJECTIVE: To characterize health care use and costs associated with high versus low AMR in patients participating in commercial health plans.

METHODS: In a commercial claims database, this study retrospectively identified patients aged 5 to 64 years on December 31, 2011, who met the HEDIS definition of asthma in the premeasurement year (January 1, 2010-December 31,2010 ) and the measurement year (January 1, 2011-December 31, 2011). Each patient was classified as having either high or low AMR based on the HEDIS definition. AMR was calculated as the ratio of controller to total asthma medications; high AMR was defined as $\geq 0.5$. Annual per-patient health care use and costs were compared in patients with high versus low AMR using (a) multivariable linear regression models to estimate mean annual number of office visits, oral corticosteroids (OCS) bursts ( $\leq 15$-day supply), and costs and (b) negative binomial models to estimate mean annual hospitalization and emergency department (ED) visits. All estimates were adjusted for age, sex, region, and Charlson Comorbidity Index score to control for differences between patients with high versus low AMR.
\end{abstract}

RESULTS: Patients were identified with high $(30,575)$ and low $(6,479)$ AMR. An average patient with high AMR had more all-cause office visits (14.1 vs. $11.0 ; P<0.001)$, fewer all-cause hospitalizations ( 0.109 vs. $0.215 ; P<0.001)$, fewer all-cause ED visits ( 0.321 vs. $0.768 ; P<0.001)$, and fewer 0 CS bursts ( 0.83 vs. $1.33 ; P<0.001$ ) than an average patient with low AMR. An average patient with high AMR had fewer asthma-related hospitalizations ( 0.024 vs. $0.088 ; P<0.001)$ and ED visits $(0.060$ vs. $0.304 ; P<0.001)$ than an average patient with low AMR. Numbers of asthma-related annual office visits were similar between the high and low AMR groups (high 2.2 vs. low 2.2; not significant). The rate of poor asthma control events ( $\geq 6$ short-acting betaagonist dispensing events or $\geq 2$ OCS bursts, asthma-related ED visits, or hospitalizations) was greater in patients with low AMR than in patients with high AMR (74.3\% vs. $26.9 \%)$. An average patient with high AMR had lower annual nonmedication costs than an average patient with low AMR $(\$ 5,733$ vs. $\$ 6,295 ; P=0.011)$. Similar trends emerged for asthma-related costs. A patient with high AMR had higher average total annual health care costs than a patient with low AMR $(\$ 9,811$ vs. $\$ 8,398 ; P<0.001)$. These increased costs primarily resulted from increased medication costs for patients with high versus low AMR ( $\$ 4,077$ vs. $\$ 2,103 ; P<0.001)$.

CONCLUSIONS: Although patients with high AMR had more office visits and higher medication (which resulted in higher overall health care) costs, their care was marked by fewer OCS bursts (indicating fewer instances of poor asthma control), fewer ED visits, and fewer hospitalizations and lower nonmedication costs than those patients with low AMR. These findings support the use of AMR as a care quality measure for patients with persistent asthma.

J Manag Care Spec Pharm. 2017;23(11):1117-24

Copyright $\odot 2017$, Academy of Managed Care Pharmacy. All rights reserved.

\section{What is already known about this subject}

Healthcare Effectiveness Data and Information Set asthma medication ratio (AMR) $\geq 0.5$ is associated with better asthma control than an $\mathrm{AMR}<0.5$.

Poor asthma control negatively effects patient health and well-being. Poor asthma control can cause health care use and costs to increase.

\section{What this study adds}

Patients with high AMR had lower rates of asthma-related emergency services (hospitalizations and emergency department visits) than patients with low AMR.

Overall costs of care for patients with high AMR were higher than costs of care for patients with low AMR

Patients with high AMR also had higher overall costs-largely driven by medication costs-but lower nonmedication-related costs than patients with low AMR.

A sthma, an inflammatory condition of the airways, causes substantial humanistic and economic burden on our society. In the United States in 2013, $8.0 \%$ of noninstitutionalized adults and $9.3 \%$ of children reported having asthma, and 3,630 people died because of asthma. ${ }^{1}$ Asthma was listed as the primary diagnosis for 439,000 hospitalizations and 14.2 million physician office visits (2010 data) and for 1.8 million emergency department (ED) visits (2011 data). ${ }^{1}$

Asthma costs total to a substantial amount each year. Using a U.S.-based survey of noninstitutionalized individuals, Sullivan et al. (2011) estimated a total of \$18 billion (2008 U.S. dollars) annual medical expenditures attributable to asthma. ${ }^{2}$ Poor asthma control (e.g., hospitalizations and ED visits) and medication costs drive much of the asthma costs. ${ }^{3-5}$

National and international asthma treatment guidelines direct the management of asthma patients. ${ }^{6,7}$ Asthma treatment focuses on symptom control and minimizing the risk of future exacerbations. Clinicians prescribe 2 types of treatments: reliever (rescue) treatments, which manage acute symptoms, and controller medications, which chronically reduce airway inflammation, control symptoms, and decrease the risk of exacerbations and lung function decline. ${ }^{7}$ Relievers include short-acting beta agonists (SABA). Controller medications 
include inhaled corticosteroids (ICS), long-acting beta agonists (LABA), ICS/LABA combinations, leukotriene modifiers, mast cell stabilizers, methylxanthines and methylxanthine combinations, and omalizumab. ${ }^{8}$ Short courses ("bursts") of oral corticosteroids (OCS) may relieve symptoms associated with an asthma exacerbation. ${ }^{7}$ Patients with severe asthma may require chronic administration of OCS. ${ }^{7}$ Well-controlled asthma is characterized by infrequent use of SABAs and steroid bursts. ${ }^{7}$

The National Committee for Quality Assurance (NCQA) developed the Healthcare Effectiveness Data and Information Set (HEDIS) to assess health care quality in health plans. ${ }^{9}$ HEDIS care quality measures for asthma include the asthma medication ratio (AMR), a ratio of asthma controller medications to the total number of asthma medications. ${ }^{8}$ This measure serves as an indicator of the quality of asthma care. The AMR $<0.5$ threshold has been used to identify patients with poorly controlled asthma ${ }^{10-12}$; however, previous literature has lacked evidence on the economic effect of high versus low AMR scores. The purpose of this study was to compare health care resource use and costs associated with high versus low AMR scores in patients with persistent asthma.

\section{Methods}

\section{Data Source}

This retrospective cohort study used a large U.S. medical claims database that includes more than 30 million covered lives from various employer-sponsored health plans and selfinsured programs. The data are derived from more than a dozen health plans and are representative of the commercially insured and Medicare population in the United States. All major regions of the United States are represented in the data. The annual attrition rate comprises 15\%-25\%. The database contains adjudicated pharmacy and medical claims submitted by providers, health care facilities, or pharmacies. Claims contain information on each physician visit, medical procedure, hospitalization, drug dispensed by a pharmacy, and test performed. The database also includes member enrollment and benefit information and limited patient demographic, provider, and hospital information.

The database complies with the Health Insurance Portability and Accountability Act. This study involved the analysis of existing data, and the subjects could not be identified by the investigator, directly or through identifiers linked to the subjects, so was exempt from human subjects review under 45 CFR $46 .{ }^{13}$

\section{Study Population}

This study included commercial health plan members, who were aged 5 to 64 years on December 31, 2011, thereby meeting the then-proposed HEDIS definition of persistent asthma. ${ }^{9}$ HEDIS cohort identification requires 2 years of data: the

\section{FIGURE 1 HEDIS Algorithm for AMR ${ }^{8}$}

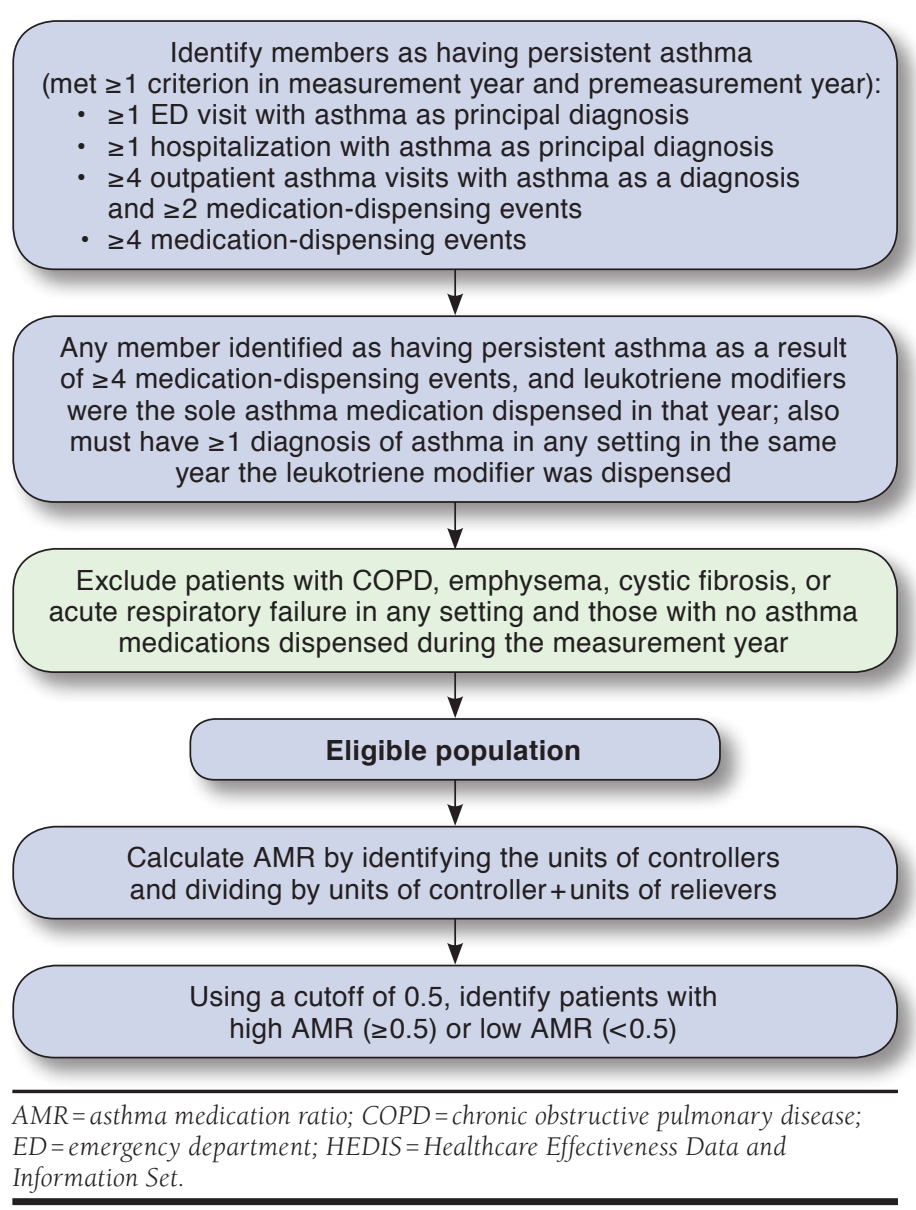

premeasurement year and the measurement year. To qualify for inclusion, patients met the HEDIS definition in both years (Figure 1). ${ }^{8}$ For the purposes of this study, we defined the premeasurement year as the period between January 1, 2010, and December 31, 2010, and the measurement year as the period between January 1, 2011, and December 31, 2011.

Patients with a diagnosis of emphysema, chronic obstructive pulmonary disease, cystic fibrosis, or acute respiratory failure were excluded. Patients also were excluded if their records showed an enrollment gap of more than 45 days in the premeasurement or measurement years.

\section{Study Measures}

Patient demographics included age, sex, region, and Charlson Comorbidity Index (CCI) score. AMR status was calculated in the following way: from pharmacy claims, each dispensing event $^{8}$ of a controller counted as 1 unit of controller, and each dispensing event of a reliever counted as 1 unit of reliever 
(Appendix A, available in online article). The AMR was calculated using the following formula:

\section{Units of Controllers}

\section{Units of Controllers + Units of Relievers}

For patients with no units of controllers or relievers, the ratio was assigned to 0 . AMR $<0.5$ indicated low AMR. ${ }^{8}$ At the time of this study, the HEDIS definition for this measure had not been finalized. When it was finalized, patients with no controllers or relievers were excluded, but by the definition available at the time of this analysis, they were not.

Evidence of poor asthma control was defined as (a) any hospitalization or ED visit with a primary diagnosis of asthma, (b) 2 or more OCS bursts ( $\leq 15$-day supply), or (c) 6 or more prescriptions for a SABA.

Health care resource measures included the use of allcause and asthma-specific outpatient, acute inpatient, and ED services. Appendix B (available in online article) details specific Current Procedural Terminology codes and International Classification of Diseases, Ninth Revision, Clinical Modification (ICD-9-CM) codes used to define events.

Health care costs included all-cause and asthma-specific annual per-patient health care costs, broken down as pharmacy and nonpharmacy (inpatient hospitalization and ED visit) costs. Costs were derived from standardized payment amounts (in U.S. dollars) reported by the data source, which reflected payments to providers based on their claims.

All-cause health care resource use and costs included all services provided, regardless of the diagnosis. Asthma-specific costs included only services that listed an asthma-specific ICD9-CM code as a primary diagnosis on a claim. All measures were calculated using data from the measurement year. Cost were not adjusted for inflation.

\section{Study Outcomes and Statistical Analyses}

Outcomes of interest were all-cause and asthma-related health services use and costs. Descriptive statistics, including means, confidence intervals (CIs), standard deviations, medians, and percentages, were reported for all measures whenever applicable. Patient characteristics (age, sex, region, and CCI score ${ }^{14,15}$ ) were stratified by high versus low AMR. For descriptive analysis, costs and health care resource use were compared between the high and low AMR groups using chi-square tests, t-tests, or log-sum tests, as appropriate.

To control for the imbalances between the high and low AMR groups, we adjusted for patient demographics as categorical variables (age groups [5-11, 12-50, 51-64], sex, region [Midwest, Northeast, South, and West]) and CCI score as a continuous variable. To conduct the adjustment, we used simple ordinary least squares regression models for costs, number of office visits, number of OCS bursts, and negative binomial models for count outcomes (e.g., number of hospitalizations and ED visits). All tests were 2-sided with a significance level

\section{TABLE 1 Baseline Patient Demographics}

\begin{tabular}{|c|c|c|c|c|}
\hline Parameter & $\begin{array}{c}\text { High AMR }^{\mathrm{a}} \\
\mathrm{n}=30,575\end{array}$ & $\begin{array}{c}\text { Low AMR }^{\mathrm{b}} \\
\mathrm{n}=6,479\end{array}$ & \begin{tabular}{|c|} 
All Patients \\
$\mathrm{N}=37,054$
\end{tabular} & $\begin{array}{c}P \\
\text { Value }\end{array}$ \\
\hline Age, years, mean (SD) & $35.2(20.5)$ & $30.1(18.3)$ & $34.3(20.2)$ & $<0.001$ \\
\hline Female, n (\%) & $17,482(57.2)$ & $3,411(52.6)$ & 20,893 (56.4) & $<0.001$ \\
\hline CCI score, mean (SD) & $1.4 \quad(1.2)$ & $1.4 \quad(1.1)$ & $1.4 \quad(1.2)$ & 0.981 \\
\hline \multicolumn{4}{|l|}{ Region, n (\%) } & 0.004 \\
\hline Midwest & $8,303(27.2)$ & $1,643(25.4)$ & $9,946(26.8)$ & \\
\hline Northeast & $3,842(12.6)$ & $814(12.6)$ & 4,656 (12.6) & \\
\hline South & $13,949(45.6)$ & $2,985(46.1)$ & $16,934(45.7)$ & \\
\hline West & $4,481(14.7)$ & $1,037(16.0)$ & $5,518(14.9)$ & \\
\hline \multicolumn{5}{|c|}{$\begin{array}{l}\text { a High } A M R \geq 0.5 \text {. } \\
{ }^{b} \text { Low } A M R<0.5 \text {. } \\
\text { AMR }=\text { asthma medication ratio; } C C I=\text { Charlson Comorbidity Index; } S D=\text { standard } \\
\text { deviation. }\end{array}$} \\
\hline
\end{tabular}

of 0.05. All data transformations and statistical analyses were performed using SAS version 9.4 (SAS Institute, Cary, NC).

\section{Results}

\section{Study Population}

After applying the inclusion and exclusion criteria, 37,054 patients met the HEDIS criteria during the premeasurement and measurement years. Of these, 30,575 (82.5\%) patients had high AMR, and 6,479 (17.5\%) patients had low AMR in the measurement year. The mean (standard deviation [SD]) AMR was $0.8(0.2)$ in the high group and $0.2(0.2)$ in the low group. There were 238 patients with no controllers or relievers in the low AMR group $(<4 \%)$, and their ratio was set to 0 . In both groups, patients were predominantly female (56.4\%) with a mean age of 34.3 years. The mean CCI score was 1.4 for both groups (Table 1).

\section{All-Cause Annual Health Care Use}

High AMR patients accumulated a higher mean number of all-cause annual office visits than their low AMR counterparts $(14.13,95 \% \mathrm{CI}=13.98-14.27$ vs. $11.00,95 \% \mathrm{CI}=10.68$ 11.32; $P<0.001$; Figure 2A). In contrast, in negative binomial models, patients with high AMR had lower adjusted mean number of hospitalizations than patients with low AMR (0.11, 95\% CI $=0.10-0.11$ vs. $0.22,95 \% \quad C I=0.20-0.23 ; \quad P<0.001$; Figure 2B). Patients with high AMR also had a lower adjusted mean number of ED visits than the low AMR group, respectively $(0.32,95 \% \mathrm{CI}=0.31-0.33$ vs. $0.77,95 \% \mathrm{CI}=0.73-0.80$; $P<0.001$; Figure 2C).

\section{Asthma-Related Annual Health Care Resource Use}

The mean number of adjusted OCS bursts was lower in the high AMR group than in the low AMR group (0.83, 95\% $\mathrm{CI}=0.81-0.84$ vs. $1.33,95 \% \mathrm{CI}=1.29-1.36 ; P<0.001$ ). Fewer patients with high AMR showed evidence of poor asthma control ( $\geq 6$ SABA fills, $\geq 2$ OCS bursts, asthma-related ED visits, 


\section{FIGURE 2 Adjusted Annual Number of Overall and Asthma-Related Visits for Office Visits,} Hospitalizations, and ED Visits ${ }^{a}$

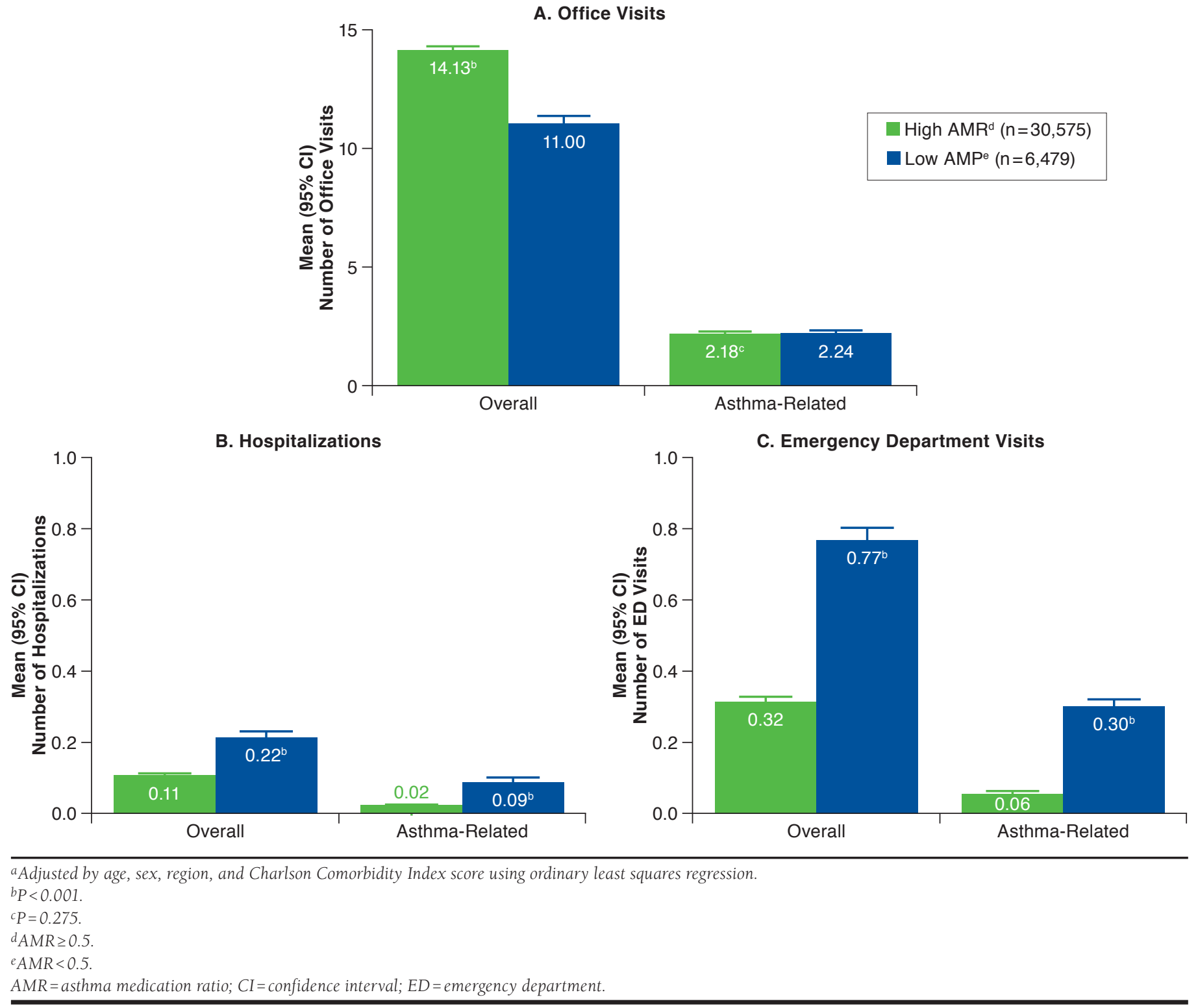

or hospitalizations) than patients with low AMR, respectively (26.9\% vs. $74.3 \%$; $P<0.001$; Figure 3).

The mean numbers of asthma-related adjusted annual hospitalizations and ED visits were lower in the high AMR group than in the low AMR group $(0.02,95 \% \mathrm{CI}=0.02-0.03$ vs. $0.09,95 \% \mathrm{CI}=0.08-0.10)$ and $0.06(95 \% \mathrm{CI}=0.057-0.063)$ versus 0.30 (95\% $\mathrm{CI}=0.29-0.32, \mathrm{P}<0.001$ ) for both (Figure $2 \mathrm{~B}$ and $2 \mathrm{C}$ ). The numbers of adjusted annual asthma-related office visits appeared similar between the 2 groups $(2.18,95 \%$
$\mathrm{CI}=2.15-2.22$ vs. $2.24,95 \% \mathrm{CI}=2.15-2.32 ; P=0.275$; data not shown in figures).

\section{Total Annual Health Care Costs}

Patients with high AMR had higher total annual adjusted mean health care costs than patients with low AMR $(\$ 9,811$, $95 \% \mathrm{CI}=\$ 9,613-\$ 10,009$ vs. $\$ 8,398,95 \% \mathrm{CI}=\$ 7,966-\$ 8,830$; $P<0.001$; Figure 4A). This difference was driven primarily by differences in annual mean medication expenditures between the high versus low AMR groups $(\$ 4,077,95 \% \mathrm{CI}=\$ 4,017-\$ 4,138$ 


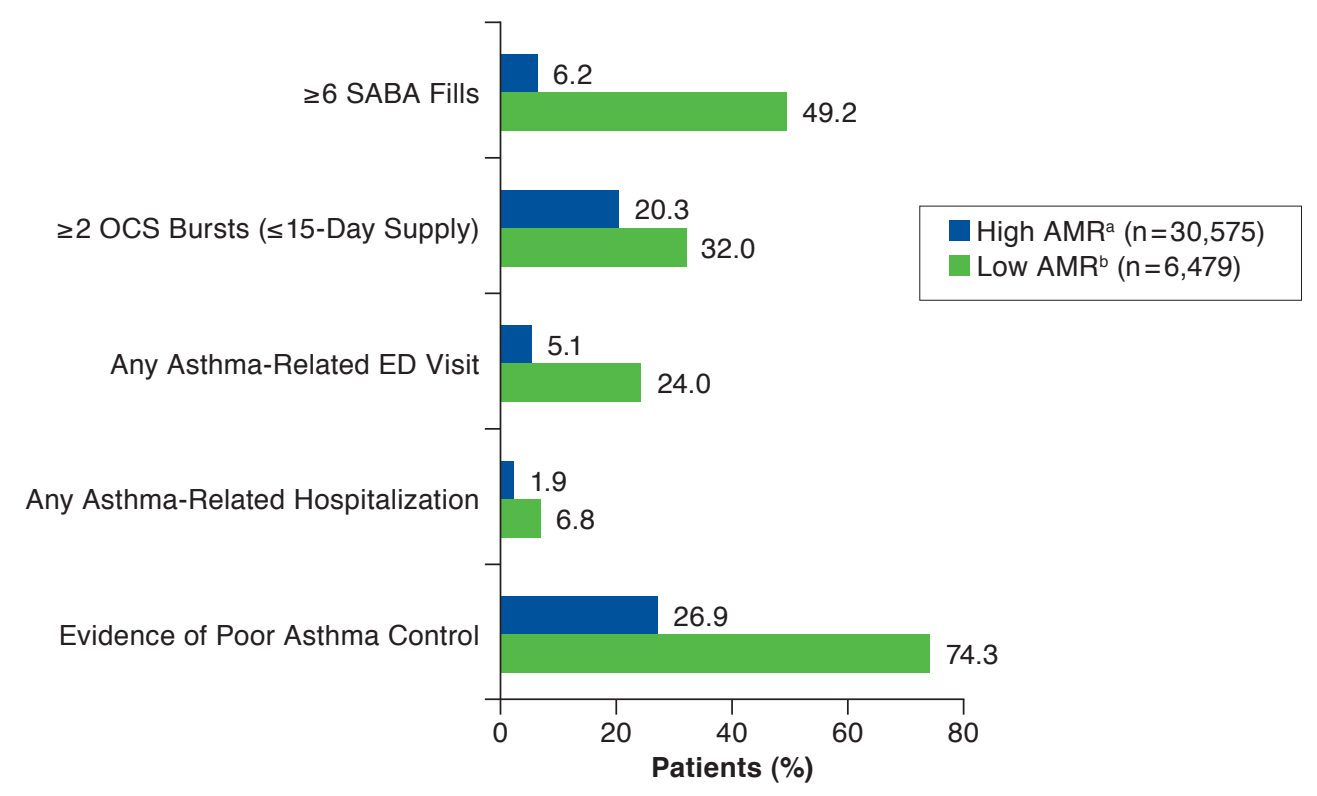

Note: $P<0.001$ for all comparisons.

${ }^{a} A M R \geq 0.5$.

${ }^{b} A M R<0.5$.

$A M R=$ asthma medication ratio; $E D=$ emergency department; $O C S=$ oral corticosteroid; $S A B A=$ short-acting beta agonist.

vs. $\$ 2,103,95 \% \mathrm{CI}=\$ 1,970-\$ 2,235)$. In contrast, annual nonmedication costs were lower in the high AMR group than in the low AMR group $(\$ 5,733,95 \% \mathrm{CI}=\$ 5,553-\$ 5,914$ vs. $\$ 6,295$, $95 \% \mathrm{CI}=\$ 5,901-\$ 6,689 ; \mathrm{P}=0.011 ;$ Figure $4 \mathrm{~A})$.

\section{Asthma-Related Annual Health Care Costs}

Asthma-related costs followed a pattern similar to that of allcause costs. Patients with high AMR had higher total adjusted mean asthma-related costs than patients with low AMR $(\$ 2,609,95 \% \mathrm{CI}=\$ 2,657-\$ 2,652$ vs. $\$ 2,236,95 \% \mathrm{CI}=\$ 2,143$ $\$ 2,330 ; P<0.001$; Figure 4B). This difference resulted from higher mean medication costs in the high rather than low AMR groups $(\$ 2,009,95 \% \mathrm{CI}=\$ 1,992-\$ 2,027$ vs. $\$ 916,95 \%$ $\mathrm{CI}=\$ 878$-\$954; $P<0.001$. Mean asthma-related nonmedication costs were lower in the high AMR group rather than in the low AMR groups $(\$ 600,95 \% C I=\$ 562-\$ 638$ vs. $\$ 1,320,95 \%$ $\mathrm{CI}=\$ 1,237-\$ 1,404 ; P<0.001)$.

\section{Discussion}

This study investigated differences in health care resource use and costs between patients with high versus low AMR. The data from a large commercial database demonstrated that a substantial proportion of asthma patients (82.5\%) had high AMR, a quality-of-care indicator adopted by the NCQA. This value concurs with an NCQA report in which $78.4 \%-79.7 \%$ of commercial plan patients were found to have high AMR in 2013.16
In this study, patients with high AMR had better asthma control and required fewer courses of OCS than patients with low AMR. Patients with high AMR had fewer asthma-related hospitalizations and ED visits than patients with low AMR. Urgent care and ED visits are 2 components of an Agency for Healthcare Research and Quality (AHRQ) Dimension of Asthma Care Management (C.2). ${ }^{17}$ Because low rates of these events are preferred to high rates, patients with high AMR were likely to have ranked more favorably than their counterparts with low AMR in these frameworks. Moreover, we found that patients with high AMR had more asthma-related office visits than those with low AMR. If this difference was driven by planned versus unplanned visits to providers, patients with high AMR also may have ranked favorably on another AHRQ measure, "high planned visits."

These findings are consistent with previous research, although most previous studies of medication ratios focused on utilization rather than cost. For example, previous to the adoption of the AMR as a quality measure, a series of studies examined its relationship with other asthma outcomes. In multiple studies, a low ratio was associated with a higher risk of ED visits and hospitalization. ${ }^{18,19}$ More recently, in an analysis of adult patients with asthma in France and Great Britain that used retrospective, coded data similar to insurance claims, patients with a high $(\geq 50 \%)$ ratio of ICS to total number of 


\section{A. Total Annual Health Care Costs}

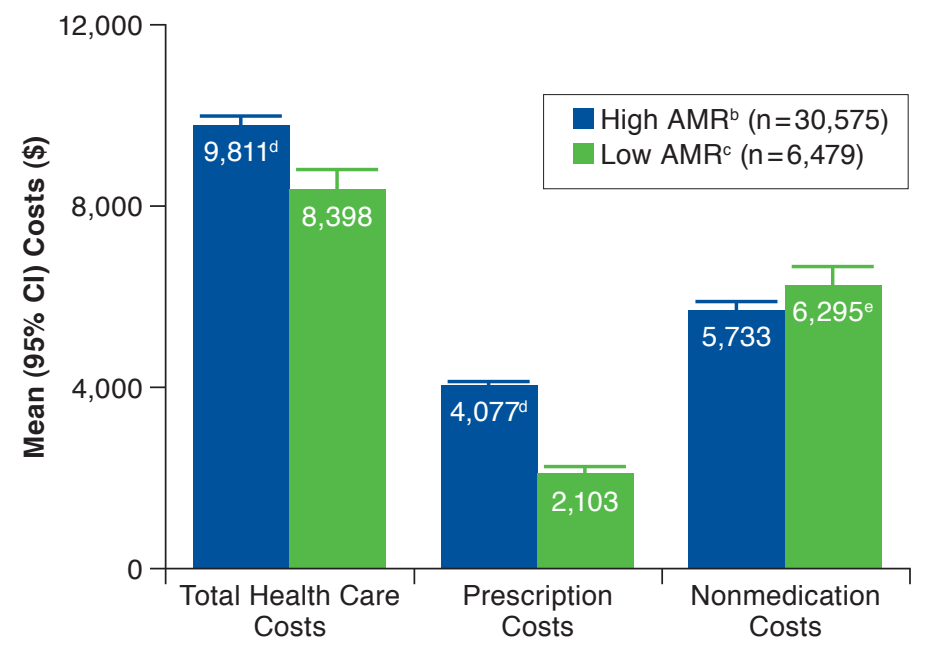

B. Asthma-Related Annual Health Care Costs

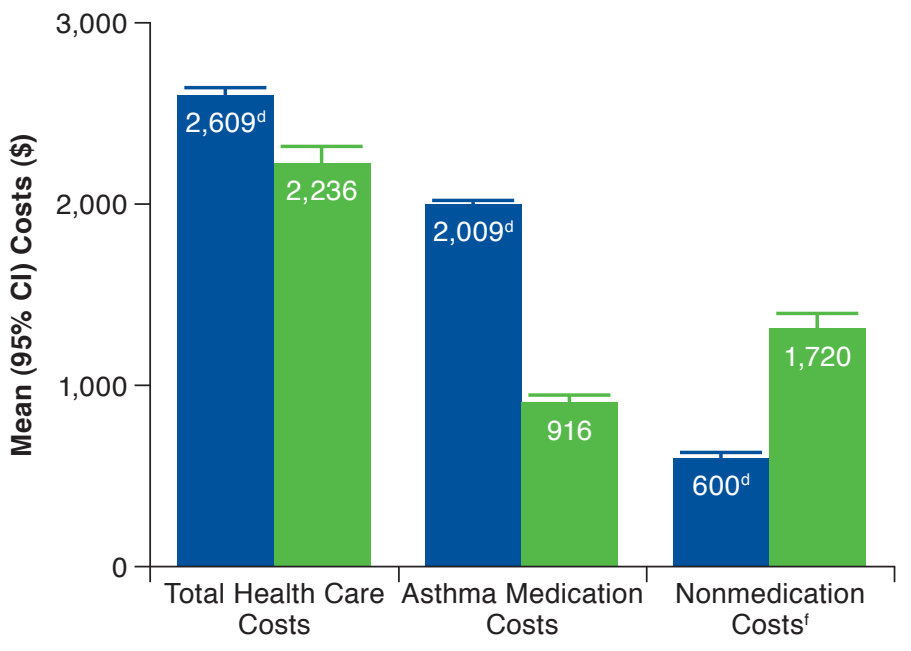

a Adjusted by age, sex, region, and Charlson Comorbidity Index score using negative binomial regression.

${ }^{b} A M R \geq 0.5$.

${ }^{c} A M R<0.5$.

${ }^{d} P<0.001$.

${ }^{e} P=0.011$.

${ }_{\text {Medical claims with primary diagnosis of asthma. }}$

AMR=asthma medication ratio; $\mathrm{CI}=$ confidence interval.

respiratory medications (similar to AMR) had a significantly lower requirement for systemic corticosteroids, antibiotics, and total asthma medications than patients with a low ratio. ${ }^{20}$

Our study was motivated in part by the lack of information on economic outcomes in patients with high versus low AMR. We found that patients with high AMR had higher overall costs than their low AMR counterparts. This finding was largely driven by higher medication costs in the group with high AMR. Also, although good asthma control was associated with higher medication costs, it was associated with lower nonmedication costs (medical costs) and fewer hospitalizations and ED visits than poor asthma control. These results demonstrate the importance of investigating benefits of quality improvement beyond the pharmacy budget when considering costs of care.

In PubMed searches, we did not find any studies that examined the question of cost in relation to performance on this HEDIS measure. However, Sullivan et al. (2014) reported that annual per-patient asthma-related medical expenditures were higher for patients who had evidence of poor asthma control than for patients whose asthma appeared to be in good control. ${ }^{3}$ This study used data from the Medical Expenditure Panel Survey, a nationally representative survey of the U.S. population, to link evidence of asthma-related ED visit, use of $>3$ canisters of SABA in past 3 months, or asthma attack in past 12 months to annual medical costs. In turn, low AMR has been associated in previous studies with more frequent $\mathrm{ED}$ visits and use of a greater number of SABA canisters. ${ }^{21,22}$ Taken together, these studies suggest that poor asthma control, whether measured by AMR or in other ways, can increase medical costs.

In addition to these economic outcomes, patients with poor asthma control are more likely to have experienced events that negatively effect overall health-related quality of life. In a study of more than 15,000 patients, quality-of-life scores were significantly worse in patients with uncontrolled asthma than in patients whose asthma appeared to be under control. ${ }^{23}$ Poorly controlled asthma was associated with an increased risk of other conditions, such as anxiety and depression. ${ }^{24}$ Asthma that is not controlled on a regular basis can result in frequent use of OCS to control asthma exacerbations. In turn, OCS use may lead to side effects, which negatively effect patient health. ${ }^{25,26}$ Investing in guideline-supported therapies for asthma management to improve asthma control may help health plans improve quality of life in patients with asthma.

\section{Limitations}

Results of this research should be interpreted in light of its limitations. This analysis did not examine or control for adherence to therapy, which has been shown to effect outcomes of care. ${ }^{27,28}$ In accordance with the HEDIS measure, calculation of AMR did not account for differences in doses per canister 
(e.g., canister weight). This study used the HEDIS 2012 definition (in place at the time of the analysis), which did not exclude patients who had no controllers or relievers. Results would likely be similar, although not identical, under the current HEDIS definition.

Although we controlled for imbalances between the high and low AMR subgroups, some unobserved confounders may have biased the results. Because complete control of risk of bias is not possible with analysis of health care claims, the association between high AMR and improved asthma control could not be interpreted as causality. The regional distribution of patients in the sample differs somewhat from the U.S. population as a whole. The South and Midwest made up $73 \%$ of the sample but represent only 59\% of the U.S. population. ${ }^{29}$ The population studied reflects the members of commercial health plans and may not be generalizable to the entire U.S. population of patients with asthma.

Cost outcomes depend on drug acquisition costs and charges for health services. Therefore, if costs in a specific health plan vary substantially from what was reported in our database, our cost outcomes may not match those observed by that plan. In addition, because of the nature of the datasets, the costs included only paid medical and pharmacy claims. Therefore, the study results omit possible copayments by patients. If copayments were included, the study results would likely be slightly different.

Because good asthma control results in less use of OCS than poor asthma control, the latter may be associated with additional costs owing to OCS-related toxicities. We have not accounted for the costs owing to adverse effects of OCS or those associated with uncontrolled asthma. In addition, we have not included in indirect costs those that are associated with loss of work, absenteeism, or reduced productivity while at work. Additional research may help further elucidate the relationship between the use of controllers, patient outcomes, health care use, and costs in asthma.

\section{Conclusions}

Patients with high AMR experienced fewer instances of poor asthma control and lower emergency health care use (e.g., hospitalizations and ED visits) than patients with low AMR. Although good asthma control was associated with higher medication costs, it also was associated with lower nonmedication costs (medical costs) and fewer hospitalizations and ED visits than poor asthma control. By monitoring HEDIS AMR, health plans may identify patients who are at high risk for asthma exacerbations with or without ED visits or hospitalizations. Interventions aiming at increasing the proportion of asthma controller medications in the total amount of asthma medications used by patients may help improve quality of asthma care.

\section{Authors}

ALLAN T. LUSKIN, MD, University of Wisconsin, Madison. EVGENIYA N. ANTONOVA, MS, PhD, U.S. Medical Affairs; KARINA RAIMUNDO, MS, U.S. Medical Affairs; and PAUL G. SOLARI, MD, New Therapeutic Areas, Genentech, South San Francisco, California. MICHAEL S. BRODER, MD, MSHS, and EUNICE CHANG, PhD, Partnership for Health Analytic Research, Beverly Hills, California.

AUTHOR CORRESPONDENCE: Karina Raimundo, MS, Genentech, 1 DNA Way, South San Francisco, CA 94080-4990. Tel.: 650.225.6220; E-mail: raimundo.karina@gene.com.

\section{DISCLOSURES}

This study was funded by Genentech. Luskin has received consulting and lecture fees, research and travel support, and payment for developing educational presentations from Genentech and has received lecture fees from Merck. Raimundo and Solari are employees of Genentech. Antonova was employed by Genentech at the time of this study. Broder and Chang are employees of Partnership for Health Analytic Research, which received funding from Genentech to conduct this research.

Study concept and design were contributed by all authors. Broder and Chang conducted analyses. All authors interpreted the data. Antonova wrote the manuscript with assistance from the other authors. All authors participated in manuscript review and revisions.

\section{ACKNOWLEDGMENTS}

Medical writing support for this manuscript was provided by Linda Wagner of Excel Scientific Solutions and funded by Genentech and Novartis Pharmaceuticals.

\section{REFERENCES}

1. Centers for Disease Control and Prevention. FastStats. Asthma. May 14 2015. Available at: http://www.cdc.gov/nchs/fastats/asthma.htm. Accessed September 11, 2017.

2. Sullivan PW, Ghushchyan VH, Slejko JF, Belozeroff V, Globe DR, Lin SL. The burden of adult asthma in the United States: evidence from the Medical Expenditure Panel Survey. J Allergy Clin Immunol. 2011;127(2):363-69.

3. Sullivan PW, Slejko JF, Ghushchyan VH, et al. The relationship between asthma, asthma control and economic outcomes in the United States. J Asthma. 2014;51(7):769-78.

4. Doz M, Chouaid C, Com-Ruelle L, et al. The association between asthma control, health care costs, and quality of life in France and Spain. BMC Pulm Med. 2013;13:15.

5. Kim SH, Kim TW, Kwon JW, et al. Economic costs for adult asthmatics according to severity and control status in Korean tertiary hospitals. J Asthma. 2012;49(3):303-09.

6. Coeytaux RR, Frasier PY, Reid A. Patient-centered outcomes for frequent headaches. Headache. 2007;47(4):480-85.

7. Global Initiative for Asthma. Global strategy for asthma management and prevention, 2017 update. Available at: http://ginasthma.org/2017-ginareport-global-strategy-for-asthma-management-and-prevention/. Accessed September 26, 2017.

8. National Quality Forum. NQF \#1800 Asthma medication ratio (AMR). Measure submission and evaluation worksheet 5.0. Available at: www. qualityforum.org/WorkArea/linkit.aspx?LinkIdentifier=id\&ItemID=69923. Accessed September 25, 2017. 
9. National Committee for Quality Assurance. HEDIS \& performance measurement. Available at: http://www.ncqa.org/HEDISQualityMeasurement. aspx. Accessed September 11, 2017.

10. Schatz M, Zeiger RS, Vollmer WM, et al. The controller-to-total asthma medication ratio is associated with patient-centered as well as utilization outcomes. Chest. 2006;130(1):43-50.

11. Andrews AL, Simpson AN, Basco WT Jr, Teufel RJ II. Asthma medication ratio predicts emergency department visits and hospitalizations in children with asthma. Medicare Medicaid Res Rev. 2013;3(4).

12. Broder MS, Gutierrez B, Chang E, Meddis D, Schatz M. Ratio of controller to total asthma medications: determinants of the measure. Am J Manag Care. 2010;16(3):170-78.

13. U.S. Department of Health and Human Services. Federal Policy for the Protection of Human Subjects. Fed Regist. 1991;56(117):28012, 28022. Available at: https://archive.hhs.gov/ohrp/documents/19910618.pdf. Accessed September 11, 2017.

14. Charlson ME, Pompei P, Ales KL, MacKenzie CR. A new method of classifying prognostic comorbidity in longitudinal studies: development and validation. J Chronic Dis. 1987;40(5):373-83.

15. Deyo RA, Cherkin DC, Ciol MA. Adapting a clinical comorbidity index for use with ICD-9-CM administrative databases. J Clin Epidemiol. 1992;45(6):613-19.

16. National Council on Quality Assurance. Use of appropriate medications for people with asthma and medication management for people with asthma. Available at: http://www.ncqa.org/report-cards/health-plans/ state-of-health-care-quality/2016-table-of-contents/asthma. Accessed September 26, 2017.

17. Agency for Healthcare Research and Quality. Table 4.2. Six quality measures for asthma: national average, best-in-class average, and poorest performing average, 2004. Content last reviewed October 2014. Available at: https://www.ahrq.gov/professionals/quality-patient-safety/quality-resources/ tools/asthmaqual/asthmacare/table4-2.html. Accessed September 25, 2017.

18. Lieu TA, Capra AM, Quesenberry CP, Mendoza GR, Mazar M. Computer-based models to identify high-risk adults with asthma: is the glass half empty or half full? J Asthma. 1999;36(4):359-70.
19. Fuhlbrigge A, Carey VJ, Adams RJ, et al. Evaluation of asthma prescription measures and health system performance based on emergency department utilization. Med Care. 2004;42(5):465-71.

20. Laforest L, Licaj I, Devouassoux G, et al. Prescribed therapy for asthma: therapeutic ratios and outcomes. BMC Fam Pract. 2015;16:49.

21. Schatz M, Nakahiro R, Crawford W, Mendoza G, Mosen D, Stibolt TB. Asthma quality-of-care markers using administrative data. Chest. 2005;128(4):1968-73.

22. Broder MS, Gutierrez B, Chang E, Meddis D, Schatz M. Ratio of controller to total asthma medications: determinants of the measure. Am J Manag Care. 2010;16(3):170-78.

23. Dean BB, Calimlim BM, Kindermann SL, Khandker RK, Tinkelman D. The impact of uncontrolled asthma on absenteeism and health-related quality of life. J Asthma. 2009;46(9):861-66.

24. Ledford DK, Lockey RF. Asthma and comorbidities. Curr Opin Allergy Clin Immunol. 2013;13(1):78-86.

25. Manson SC, Brown RE, Cerulli A, Vidaurre CF. The cumulative burden of oral corticosteroid side effects and the economic implications of steroid use. Respir Med. 2009;103(7):975-94.

26. Luskin AT, Antonova EN, Broder MS, Chang EY, Omachi TA, Ledford DK. Healthcare resource use and costs associated with possible side effects of high oral corticosteroid use in asthma: a claims-based analysis. Clinicoecon Outcomes Res. 2016;8:641-48.

27. Tan H, Sarawate C, Singer J, et al. Impact of asthma controller medications on clinical, economic, and patient-reported outcomes. Mayo Clin Proc 2009;84(8):675-84.

28. Zafari Z, Lynd LD, FitzGerald JM, Sadatsafavi M. Economic and health effect of full adherence to controller therapy in adults with uncontrolled asthma: a simulation study. J Allergy Clin Immunol. 2014;134(4):908-15.

29. Mackun P, Wilson S. Population distribution and change: 2000 to 2010. 2010 Census Briefs. March 2011. Available at: https://www.census.gov/prod/ cen2010/briefs/c2010br-01.pdf. Accessed September 11, 2017. 


\begin{tabular}{l|l}
\multicolumn{1}{c}{ APPENDIX A } & \multicolumn{1}{c}{$\begin{array}{c}\text { Listing of Included Asthma } \\
\text { Medications }\end{array}$} \\
\hline Description & \multicolumn{1}{c}{ Prescriptions } \\
\hline Asthma controller medications & \multicolumn{1}{c}{$\begin{array}{l}\text { Dyphylline-guaifenesin, guaifenesin- } \\
\text { theophylline, or potassium } \\
\text { iodide-theophylline }\end{array}$} \\
\hline Antiasthmatic combinations & Omalizumab \\
\hline Antibody inhibitor & $\begin{array}{l}\text { Budesonide-formoterol or } \\
\text { fluticasone-salmeterol }\end{array}$ \\
\hline Inhaled steroid combinations & $\begin{array}{l}\text { Beclomethasone, budesonide, } \\
\text { ciclesonide, flunisolide, fluticasone } \\
\text { CFC free, mometasone, or } \\
\text { triamcinolone }\end{array}$ \\
\hline Inhaled corticosteroids & Montelukast, zafirlukast, or zileuton \\
\hline Leukotriene modifiers & $\begin{array}{l}\text { Arformoterol, formoterol, or } \\
\text { salmeterol }\end{array}$ \\
\hline Long-acting inhaled beta-2 agonists & Cromolyn or nedocromil \\
\hline Mast cell stabilizers & $\begin{array}{l}\text { Aminophylline, dyphylline, } \\
\text { oxtriphylline, or theophylline }\end{array}$ \\
\hline Methylxanthines & $\begin{array}{l}\text { Albuterol, levalbuterol, } \\
\text { metaproterenol, or pirbuterol }\end{array}$ \\
\hline Asthma reliever medications & \\
\hline Short-acting inhaled beta-2 agonists & \\
\hline CFC=chlorofluorocarbon. &
\end{tabular}

\begin{tabular}{|c|c|c|}
\hline \multicolumn{3}{|c|}{ APPENDIX B } \\
\hline Description & CPT Code & UB Revenue \\
\hline Outpatient & $\begin{array}{l}\text { 99201-99205, 99211-99215, } \\
99217-99220,99241-99245, \\
99341-99345,99347-99350, \\
99382-99386,99392-99396, \\
99401-99404,99411,99412, \\
99420,99429\end{array}$ & $\begin{array}{l}\text { 051x, 0520-0523, 0526-0529, } \\
057 x-059 x, 0982,0983\end{array}$ \\
\hline $\begin{array}{l}\text { Acute } \\
\text { inpatients }\end{array}$ & $\begin{array}{l}\text { 99221-99223, 99231-99233, } \\
99238,99239,99251-99255, \\
99291\end{array}$ & $\begin{array}{l}\text { 010x, 0110-0114, 0119, } \\
0120-0124,0129,0130-0134, \\
0139,0140-0144,0149, \\
0150-0154,0159,016 x, \\
020 x, 021 x, 072 x, 0987\end{array}$ \\
\hline $\begin{array}{l}\text { Emergency } \\
\text { department }\end{array}$ & $99281-99285$ & $045 x, 0981$ \\
\hline
\end{tabular}

